\section{Catastrophic Reaction}

Dawn E. Bouman

Neuropsychology and Medical Psychology, University of Cincinnati, Department of Neurology and Rehabilitation Medicine, Cincinnati, OH, USA

\section{Synonyms}

Catastrophic condition

\section{Definition}

This term coined by Goldstein (1948) describes acute distress, agitation, and disorganized behavior occurring when overwhelmed by a situation with which the person cannot cope, typically following brain injury or other neurological impairment. Rapid and extreme anxiety, depression, and frustration can result when a person becomes overstimulated or overwhelmed with a task that has become too difficult or is perceived as being too difficult. Typically, persons experiencing catastrophic reactions are not fully aware of their increasing lability and cannot respond to logic and reason, but they benefit from decreased demands and calm reassurance. Catastrophic reactions were initially thought to be associated only with dominant hemisphere damage and accompanying language impairment, but they can follow any neurological problem that interferes with adaptive coping and executive functioning.

\section{Cross-References}

\author{
- Agitation \\ - De-Escalation \\ - Executive Functioning \\ - Frustration Tolerance
}

\section{References and Readings}

Callahan, C. D. (2009). The assessment and rehabilitation of executive function disorders. In B. Johnstone \& H. H. Stonnington (Eds.), Rehabilitation of neuropsychological disorders (2nd ed., pp. 75-106). Philadelphia: Psychology Press.

Goldstein, K. (1948). Language and language disturbances: Aphasic symptom complexes and their significance for medicine and theory of language. New York: Grune and Stratton.

Holland, D., \& Larimore, C. (2009). The assessment and rehabilitation of language disorders. In B. Johnstone \& H. H. Stonnington (Eds.), Rehabilitation of neuropsychological disorders (2nd ed., pp. 137-166). Philadelphia: Psychology Press.

Lezak, M. D., Howieson, D. B., Bigler, E.D., \& Tranel D. (2012). Neuropsychological assessment (5th ed., p. 66). New York: Oxford University Press. 